\title{
APPRAISAL OF WINE COLOR AND PHENOLS FROM A NON-INVASIVE GRAPE BERRY FLUORESCENCE METHOD
}

\author{
Maria-Paz DIAGO*, Zenaida GUADALUPE, Javier BALUJA, \\ Borja MILLAN and Javier TARDAGUILA \\ Instituto de Ciencias de la Vid y del Vino (University of La Rioja, CSIC, Gobierno de La Rioja), \\ 26006 Logroño, Spain
}

\begin{abstract}
Aims: To investigate the relationships between the anthocyanin content of Vitis vinifera L. cvs. Tempranillo and Graciano grapes, determined in the vineyard and in the winery by a non-invasive fluorescence sensor, and the final wine color and phenolic traits.
\end{abstract}

Methods and results: Grape anthocyanin and phenol measurements were conducted with a hand-held, non-destructive fluorescence-based proximal sensor, in the vineyard (on clusters hanging on the vine) and at the winery (on harvested clusters in boxes) in two seasons. The anthocyanin fluorescence indices, ANTH_RG and FERARI, were found to significantly correlate with the wine color density $\left(\mathrm{R}^{2}\right.$ ranged from 0.51 to 0.82$)$ and total phenol index ( $\mathrm{R}^{2}$ ranged from 0.44 to 0.87$)$, regardless that the measurements were made in the vineyard or in the winery. Similarly, the CIELAB parameters defining lightness $\left(\mathrm{L}^{*}\right)$, hue angle $\left(h^{*}\right)$ and coordinate $b^{*}$ (yellow-blue component of the wine tonality) also showed significant relationships ( $\mathrm{R}^{2}$ ranged from 0.55 to 0.74 ) with ANTH_RG and FERARI indices in very young wines.

Conclusion: This preliminary study showed that satisfactory estimation of the final wine color and phenolic characteristics can be obtained from fast, non-destructive measurements in grapes, using a fluorescence-based sensor, either in the vineyard or in the winery.

Significance and impact of the study: This is the first work showing the capabilities of the chlorophyll fluorescence of grapes to estimate the final wine color and phenolic traits. This information could help the wine industry make more informed decisions regarding selective harvest and winemaking in a fast and cost-effective way.

Key words: wine color density, total phenol index, fluorescencebased sensor, CIELAB, grapevine

\section{Résumé}

Objectifs : Rechercher les rapports entre la teneur en anthocyanes des baies des cépages Tempranillo et Graciano (Vitis vinifera L.), déterminée avec un capteur optique, portable et non destructif (qui mesure l'autofluorescence des fruits) au vignoble et au cellier, et les caractéristiques phénoliques et de couleur des vins.

Méthodes et résultats : Les anthocyanes et les polyphénols des baies ont été mesurés avec un capteur optique, portable et non destructif, au vignoble (sur les raisins des vignes) et au chai (sur les raisins vendangés) sur deux années. Les indices de teneur en anthocyanes, ANTH RG et FERARI, ont montré des corrélations significatives avec l'intensité colorante des vins $\left(\mathrm{R}^{2}\right.$ a varié entre 0.51 et 0.82$)$ ainsi qu'avec l'indice de polyphénols totaux $\left(\mathrm{R}^{2} \mathrm{a}\right.$ varié entre 0.44 et 0.87 ), indépendamment que les mesures aient été faites au vignoble ou au chai. De la même façon, les composantes CIELAB de la clarté $\left(\mathrm{L}^{*}\right)$, de la teinte $\left(\mathrm{h}^{*}\right)$ et de la coordonnée $\mathrm{b}^{*}$ (gamme de l'axe jaune - bleu de la teinte des vins) ont montré des rapports significatifs $\left(\mathrm{R}^{2}\right.$ a varié entre 0.55 et 0.74 ) avec les indices ANTH_RG et FERARI dans les vins jeunes.

Conclusion : Les résultats de cette étude préliminaire ont montré qu'il est possible de faire une estimation satisfaisante de la couleur et des caractéristiques phénoliques des vins rouges à partir des mesures de fluorescence sur les raisins, rapides et non destructives, au vignoble de même qu'au chai.

Signification et impact de l'étude : C'est le premier travail qui vise à montrer les capacités de la fluorescence de la chlorophylle des raisins pour estimer la couleur et les traits phénoliques du vin final. Cette information pourrait aider l'industrie du vin à prendre des décisions en ce qui concerne la récolte sélective et la vinification d'une manière rapide et rentable.

Mots clés : intensité colorante du vin, indice de phénols totaux, capteur de fluorescence, CIELAB, vigne 


\section{INTRODUCTION}

Anthocyanins and phenols in grapes are very important compounds for defining wine quality (Iland et al., 2004; Kennedy, 2010). Wine color and mouthfeel are key parameters evaluated in sensory analysis and may condition preferences on the other organoleptic characteristics of the wine (Glories, 1984; Somers and Evans, 1974). In this respect, a recent work has shown that wines with a dark red color and large concentrations of anthocyanins and polyphenols were better rated by wine experts in terms of aging potential, which is directly related to quality perception (Campo et al., 2010).

The prediction of the color and phenolic composition of red wines from the phenolic profiles of the grapes has been studied by several authors (Iland, 1987; González-Neves et al., 2004, 2010; Romero-Cascales et al., 2005; Jensen et al., 2008; Kontoudakis et al., 2010), although through extensive and destructive wet chemistry procedures (Glories, 1984; Iland et al., 2004), which are timeconsuming and labor intensive.

One of the classical and official methods to measure the color of wines was established by the "Commission Internationale de l'Éclairage" (CIE, 1986) and is based on the CIE 1976 (L*, a*, and $b^{*}$ ) color space (CIELAB). This method for color representation attempts to reproduce the visual sensation perceived by observers. The CIELAB color space is a Cartesian coordinate scheme defined by three colorimetric coordinates, $\mathrm{L}^{*}, \mathrm{a}^{*}$, and $b^{*}$, representing lightness, red-green and yellow-blue contributions, respectively. Several works have been conducted on grape berry, juice, and wine color evaluation using the CIELAB system. There has also been much research on the anthocyanin composition and content of grapes and wines (Prodanov et al., 2005; Rolle and Guidoni, 2007; Esparza et al., 2009; Garcia-Marino et al., 2012), however, few studies have reported the relationship between color parameters using CIELAB coordinates and the visual chromaticity appearance (Carreño et al., 1995) or the anthocyanin composition of grape berries (Liang et al., 2011).

Nowadays, factors like fast and low-cost analysis, together with non-invasive or minimal sample preparation methods, are of paramount importance in the modern wine industry (Cozzolino et al., 2006; González-Caballero et al., 2010). Recently, non-invasive techniques such as hyperspectral imaging (Fernandes et al., 2011) and NIR spectroscopy (Ferrer-Gallego et al., 2011) have been used for assessing the anthocyanin content of grapes in the laboratory. Furthermore, in the last few years, the anthocyanin content of grapes has also been measured by a non-destructive method known as the chlorophyll fluorescence screening method (Agati et al., 2007; Cerovic et al., 2008), and several fluorescence indices, such as ANTH_RG and FERARI, have been proposed (Ben Ghozlen et al., 2010a, b). ANTH_RG and FERARI indices, measured either in the laboratory or in the vineyard, have been successfully correlated with the anthocyanin content in grape berries (Cerovic et al., 2008; Ben Ghozlen et al., 2010a, b), although the correlation was negative for ANTH_RG and positive for FERARI in mature berries.

In the vineyard, this non-invasive technology allows the measurement of a large number of clusters without altering the yield, hence enabling the monitoring of the anthocyanin content of the berry throughout grape ripening (Tuccio et al., 2011). Additionally, the chlorophyll fluorescence sensor has also been used for studying the spatial variability of the grape anthocyanin content in the vineyard and its relationship with vine vigor and yield (Baluja et al., 2012), as well as for mapping grape quality properties in precision viticulture (Bramley et al., 2011).

Some works have demonstrated the capability of this fluorescence sensor in determining the anthocyanin content in grapes (Cerovic et al., 2008; Ben Ghozlen et al., 2010a, b; Bramley et al., 2011; Tuccio et al., 2011). Nevertheless, the relationships between the fluorescence measurements on berries and the color and phenolic features in wines have not been investigated yet. In this way, the potential application of this sensor to estimate the wine color and phenolic traits would be of great interest for the wine industry. Therefore, the aim of this study was to test the applicability of this recent fluorescence sensor as a non-invasive and rapid technique in the vineyard and winery conditions for estimating the color and phenolic features of Tempranillo and Graciano (Vitis vinifera L.) wines.

\section{MATERIALS AND METHODS}

\section{Experimental layout}

The study was carried out in two commercial vineyards located in the Rioja (season 2009) and Navarra appellations (season 2010), Spain. In 2009, the experimentation was carried out in a dry-farmed vineyard located in Ollauri (lat. $42^{\circ} 31^{\prime} \mathrm{N}$, long. $2^{\circ}$ 49’W; 527 m), La Rioja, Spain (site 1) on separated 
plots of Tempranillo (4 ha) and Graciano (2.3 ha) (Vitis vinifera L.) grapevines grafted onto $110 \mathrm{R}$ rootstock and planted in 1996 and 1995, respectively, in a clay-loam soil. Vines of both varieties were spaced at $2.70 \mathrm{~m} \mathrm{x} 1.15 \mathrm{~m}$ (inter- and intra-row), and row orientation was east-west. The vines were spur-pruned (to retain 12 buds per vine) in a bilateral cordon and trained to a vertically shoot-positioned (VSP) trellis system. In 2010, the experimentation was conducted in a vineyard (2.2 ha) located in Ayegui (lat. 42 $38^{\prime} 53^{\prime \prime}$, long. $2^{\circ} 2^{\prime}$ $25^{\prime \prime} ; 518 \mathrm{~m}$ ), Navarra, Spain (site 2) on Tempranillo grapevines grafted onto $41 \mathrm{~B}$ rootstock and planted in 2004 in a sandy-clay soil. The vines were spaced at $2.4 \mathrm{~m} \times 1.6 \mathrm{~m}$, and row orientation was north-south. Vines were trained to a vertically shoot-positioned (VSP), spur-pruned cordon retaining 16 nodes per linear meter/vine. At site 1 , a number of 75 vines of Tempranillo and 42 vines of Graciano, corresponding to 25 and 14 experimental blocks, respectively, with three adjacent vines in each block, were randomly located within the vineyard. Similarly, 39 vines of Tempranillo, corresponding to 13 experimental blocks, with three adjacent vines per block, were also randomly labeled in the site 2 vineyard.

\section{Fluorescence measurements in the vineyard and in the winery}

Vineyard and winery fluorescence measurements were conducted with a hand-held, non-destructive fluorescence-based proximal sensor called Multiplex $3^{\mathrm{TM}}$ (Force-A, Orsay, France), as described in detail by Ben Ghozlen et al. (2010a). The Multiplex $3^{\mathrm{TM}}$ device had six Red-Blue-Green (RGB) matrices light sources, at $470 \mathrm{~nm}$ (Blue, B), $516 \mathrm{~nm}$ (Green, G) and $635 \mathrm{~nm}$ (Red, R), and three synchronized detectors for fluorescence recording: yellow (YF), red (RF) and far-red (FRF). The fluorescence indices linked to the anthocyanin content measured in this work were ANTH_RG and FERARI, which are based on the far-red fluorescence responses (FRF) excited by red (FRF_R) and green light (FRF_G) (Ben Ghozlen et al., 2010a). Likewise, the fluorescence indices are defined as:

$$
\begin{aligned}
& \text { ANTH_RG }=\log (\text { FRF_R } / \text { FRF_G }) \\
& \text { FERARI }=\log (5000 / \text { FRF_R })
\end{aligned}
$$

In 2009, fluorescence measurements were conducted both in the vineyard (directly on clusters hanging on the vines) and at the experimental winery (on the clusters harvested in boxes prior to winemaking), whereas in 2010 , only vineyard measurements were carried out.

In both sites, vineyard measurements with the Multiplex $3^{\mathrm{TM}}$ were performed two days before harvest on three clusters per vine (covering the exposed side of each cluster, and holding the sensor against the cluster). In total, for each experimental block, 9 measurements, on 9 different clusters (1 measurement per cluster) were taken, representing approximately $15 \%$ of the fruit of each block. Winery measurements were conducted with the Multiplex $3^{\mathrm{TM}}$ device on the harvested clusters in each box (boxes were of $15 \mathrm{~kg}$ each) corresponding to a single experimental block. The fruit from each experimental block became an individual fermentation lot. A number of 15 fluorescence measurements were conducted for each fermentation lot (one measurement per cluster), representing $50 \%$ of the fruit. Given the sensor design, a surface of $8 \mathrm{~cm}^{2}$ per cluster was targeted in each measurement.

\section{Winemaking and wine color and phenolic indices assessment}

At site 1, the Tempranillo and Graciano vines were completely harvested on September 25 (23.5 ${ }^{\circ}$ Brix) and October 7, 2009 (22.3 ${ }^{\circ}$ Brix), respectively. For both cultivars, all clusters of the three vines corresponding to each experimental block were mixed so as to end up with 25 different grape lots for the winemaking of Tempranillo and 14 grape lots for Graciano. At site 2, the Tempranillo vines were harvested on October 15, 2010 (24.5 ${ }^{\circ}$ Brix), and the fruit of the three vines per block was mixed, ending up with 13 different lots for winemaking.

Once harvested, grape lots were transported to the winery of the University of Rioja, measured with the Multiplex $3^{\mathrm{TM}}$ sensor at the winery crush pad, and stored for 12 hours at $4.5^{\circ} \mathrm{C}$ in a dark room. Wine fermentations were conducted according to the microscale fermentation set-up proposed by Sampaio et al. (2007). Grapes were destemmed and slightly crushed with a crusher-destemmer (Master, Enomundi, Zaragoza, Spain). Sulfur dioxide was added at a rate of $60 \mathrm{mg} / \mathrm{kg}$ and musts inoculated with yeast (Saccharomyces cerevisiae, Zymaflore, RJA64 Lallemand) at a rate of $20 \mathrm{~g} / \mathrm{hl}$. The fermentation temperature was kept between 27$31^{\circ} \mathrm{C}$. Alcoholic fermentations were completed after ten days, but extended maceration was allowed for five more days in all cases. After fermentation, the wines were manually racked off 
and pressed. For each micro-fermentor, the free-run and pressed wine fractions were blended, added with sulfur dioxide at $30 \mathrm{mg} / \mathrm{l}$, and stored at $16^{\circ} \mathrm{C}$ in a dark room. Color and phenolic features of the wines were determined 15 days after completion of alcoholic fermentation. In all cases, the wines had not undergone malolactic fermentation. Color density (CD) was calculated by adding the absorbance readings at 420,520 and $620 \mathrm{~nm}$ (OIV, 2009), and total phenol index (TPI) was calculated by the absorbance reading at $280 \mathrm{~nm}$ as described by the OIV method (OIV, 2009). All analyses were run in triplicate. For the Tempranillo wines of site 2 , rectangular CIELAB coordinates, such as $L^{*}$ (lightness), $a^{*}$ (red-green coordinate), $b^{*}$ (yellowblue coordinate) and the $\mathrm{C}^{*}$ (chroma) and $\mathrm{h}^{*}$ (hue) cylindrical coordinates (using D65 illuminant and CIE $196410^{\circ}$ standard observer conditions) were computed from the CIE (1986) tristimulus values (X, Y and $\mathrm{Z}$ ) using the simplified method described by Pérez-Caballero et al. (2003). This method has been proposed as an OIV method for color determination (Negueruela et al., 2001). All spectroscopic analyses were carried out on a Lambda 20 UV/VIS spectrophotometer (PerkinElmer, Norwalk, USA).

\section{Statistical analysis}

Computation of the coefficients of determination and assessment of the statistical significance of all correlations between fluorescence indices and wine color and phenolic parameters were conducted with the SPSS statistical package (v15.0, IBM, NY, USA).

\section{RESULTS AND DISCUSSION}

The correlations between two important wine parameters, color density (CD) and total phenol index (TPI), and the fluorescence indices, ANTH_RG and FERARI, measured on grape clusters in the vineyard in 2009 for Tempranillo

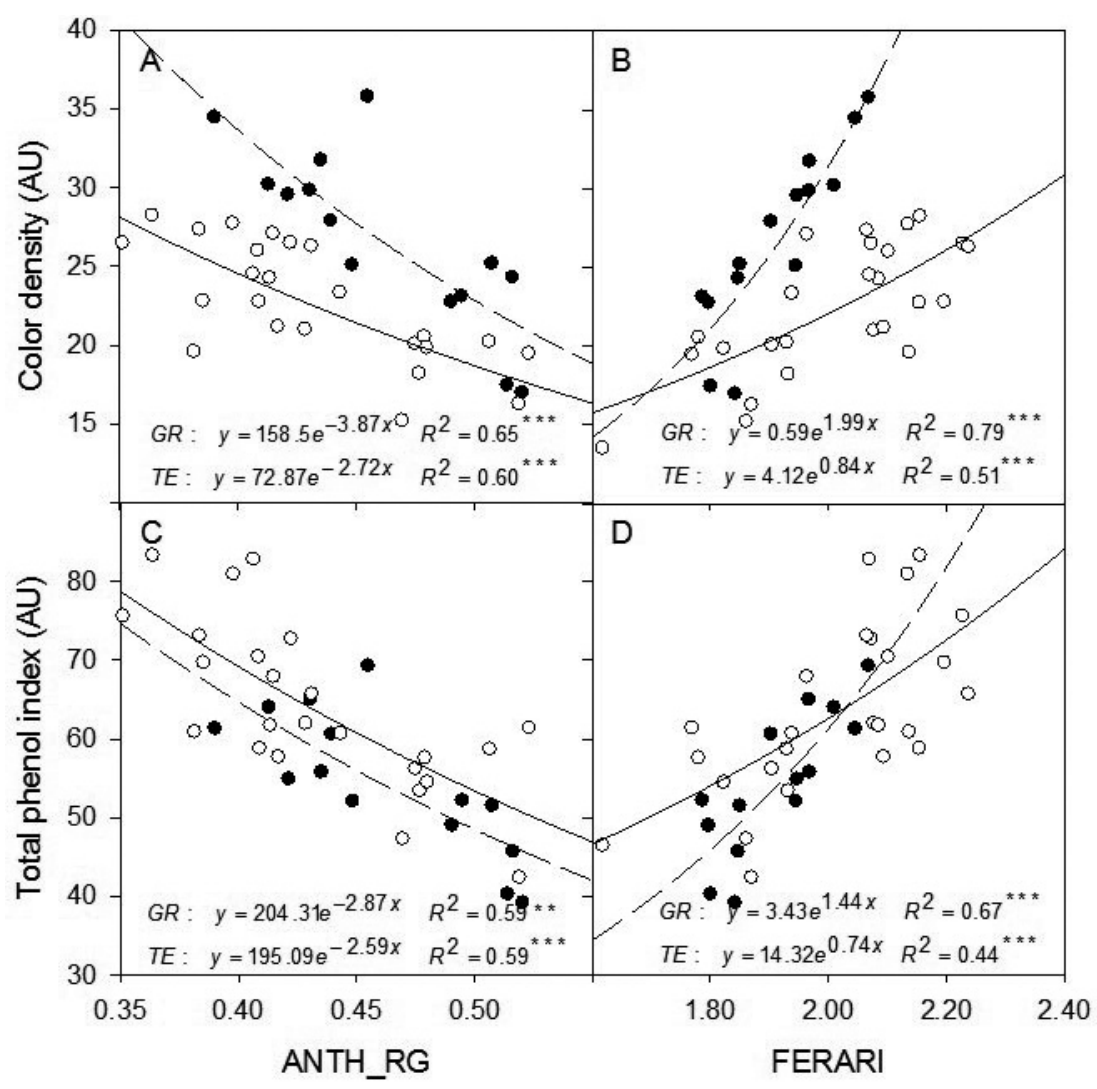

Figure 1 - The relationship between the wine color density $(\mathrm{A}, \mathrm{B})$ and total phenol index $(\mathrm{C}, \mathrm{D})$ and the fluorescence indices, ANTH_RG (A, C) and FERARI (B, D), determined in the vineyard on three vines per experimental block (three clusters per vine), for Graciano (GR, black dots) and Tempranillo (TE, TM white dots) cultivars at site 1 (season 2009). ANTH_RG and FERARI values represent averages per experimental block (3 vines $x 3$ clusters per vine). Lines represent the exponential regressions for Graciano (dashed line) and Tempranillo (continuous line). Coefficients of determination $\left(\mathbf{R}^{2}\right)$ and their statistical significance: *,**,*** indicate statistical significance at $P<0.05, P<0.01$, or $P<0.001$, respectively. $(\mathrm{n}=25$ for Tempranillo and $\mathrm{n}=14$ for Graciano). 
and Graciano cultivars are shown in Figure 1. The relationships for the two fluorescence indices were very similar in the two varieties. CD and TPI exhibited a significant negative exponential correlation with ANTH_RG (Figures 1A and C), with $\mathrm{R}^{2}$ values (coefficients of determination) of $\sim$ 0.60 , whereas both $\mathrm{CD}$ and TPI were found to significantly increase with FERARI (Figures 1B and D), following an exponential function, with $\mathrm{R}^{2}$ values ranging from 0.44 to 0.79 . The fact that the sign of the correlation differed between the two fluorescence indices was expected, and it reflected the response of each of these indices to the anthocyanin and phenolic contents in grape berries (Ben Ghozlen et al., 2010a). Likewise, our results are in agreement with those presented by several authors, who observed a negative response of ANTH RG with the anthocyanin content of mature berries of Pinot Noir and Pinot Meunier (Ben Ghozlen et al., 2010a), Shiraz (Bramley et al., 2011) and Aleatico (Tuccio et al., 2011) at harvest, and a positive relationship with FERARI.

Confirming the results obtained in 2009, in 2010 the relationships between the in-vineyard measured fluorescence indices and CD and TPI for Tempranillo at site 2 (Table 1) were also described by exponential functions and their determination coefficient values were similar to those observed for Tempranillo and Graciano at site 1.

The correlations between the fluorescence measurements taken at the winery in 2009 (on the fermentation lots in boxes) and the CD and TPI values of the wines are presented in Figure 2. Exponential decay and growth functions were observed for ANTH RG (Figures 2A and C) and FERARI (Figures $2 \mathrm{~B}$ and $\mathrm{D}$ ), respectively, for both grape cultivars. In Graciano, the $\mathrm{R}^{2}$ values for the correlations with $\mathrm{CD}$ and TPI ranged from 0.82 to 0.87 . However, in Tempranillo, larger $\mathrm{R}^{2}$ values
(0.75-0.78) were observed when the fluorescence indices were correlated to the wine $\mathrm{CD}$ than when correlated to the TPI index $\left(\mathrm{R}^{2} \sim 0.65\right)$. Despite the fact that ANTH RG and FERARI are described to be quite specific for anthocyanins (Agati et al., 2007), these indices, either determined in the vineyard or at the winery, seemed to work satisfactorily too when estimating the total phenolic content of wines, probably because anthocyanins were the predominant polyphenols in the studied wines.

Comparing the performance of ANTH_RG and FERARI, their coefficients of determination were alike when these fluorescence indices were determined in clusters in the vineyard (Figure 1 and Table 1) or at the winery (Figure 2), although higher $\mathrm{R}^{2}$ values were observed for ANTH_RG in some cases, especially at site 2 . This could be explained by the fact that there are two main factors that may affect measurements with the Multiplex $3^{\mathrm{TM}}$ device on clusters: the distance at which the measurement is taken, and the size and architecture of the cluster (Ben Ghozlen et al., 2010a). Despite the fact that all cluster measurements were conducted by holding the sensor against the cluster (the device literally touched the grape cluster), not all the berries comprised in the $8 \mathrm{~cm}^{2}$ round area of measurement were at equal distance from the reflectance detectors, and these divergences, together with the number of berries covered by the $8 \mathrm{~cm}^{2}$ measurement area, are strongly influenced by the cluster size and morphology. When field measurements are taken, these factors are said to be more critical for FERARI than for ANTH RG, since the later is calculated as the ratio of two individual signals (Ben Ghozlen et al., 2010a).

In the present work, the fluorescence indices, ANTH_RG and FERARI, provided satisfactory

Table 1 - Relationships between the fluorescence indices (ANTH_RG and FERARI) measured in the vineyard and wine color density and total phenol index, both expressed in absorbance units, for Tempranillo at site 2.

Exponential functions $\left(y=a \cdot e^{b x}\right)$ and determination coefficients $\left(R^{2}\right)$ of the correlations $(n=13)$.

Statistical significance is expressed as follows: (*) for $P<0.05,(* *)$ for $P<0.01$ and $(* * *)$ for $P<0.001$.

\begin{tabular}{|lcc|}
\hline \multicolumn{1}{|c}{ Relationship } & Function & $\mathrm{R}^{2}$ \\
\hline Color Density vs ANTH_RG & $\mathrm{y}=44.3 \mathrm{e}^{-1.99 \mathrm{x}}$ & $0.89^{* * *}$ \\
Color Density vs FERARI & $\mathrm{y}=8.42 \mathrm{e}^{0.51 \mathrm{x}}$ & $0.60^{* *}$ \\
Total phenol index vs ANTH_RG & $\mathrm{y}=116.6 \mathrm{e}^{-1.67 \mathrm{x}}$ & $0.62^{* *}$ \\
Total phenol index vs FERARI & $\mathrm{y}=34.7 \mathrm{e}^{0.52 \mathrm{x}}$ & $0.59^{* *}$ \\
\hline
\end{tabular}




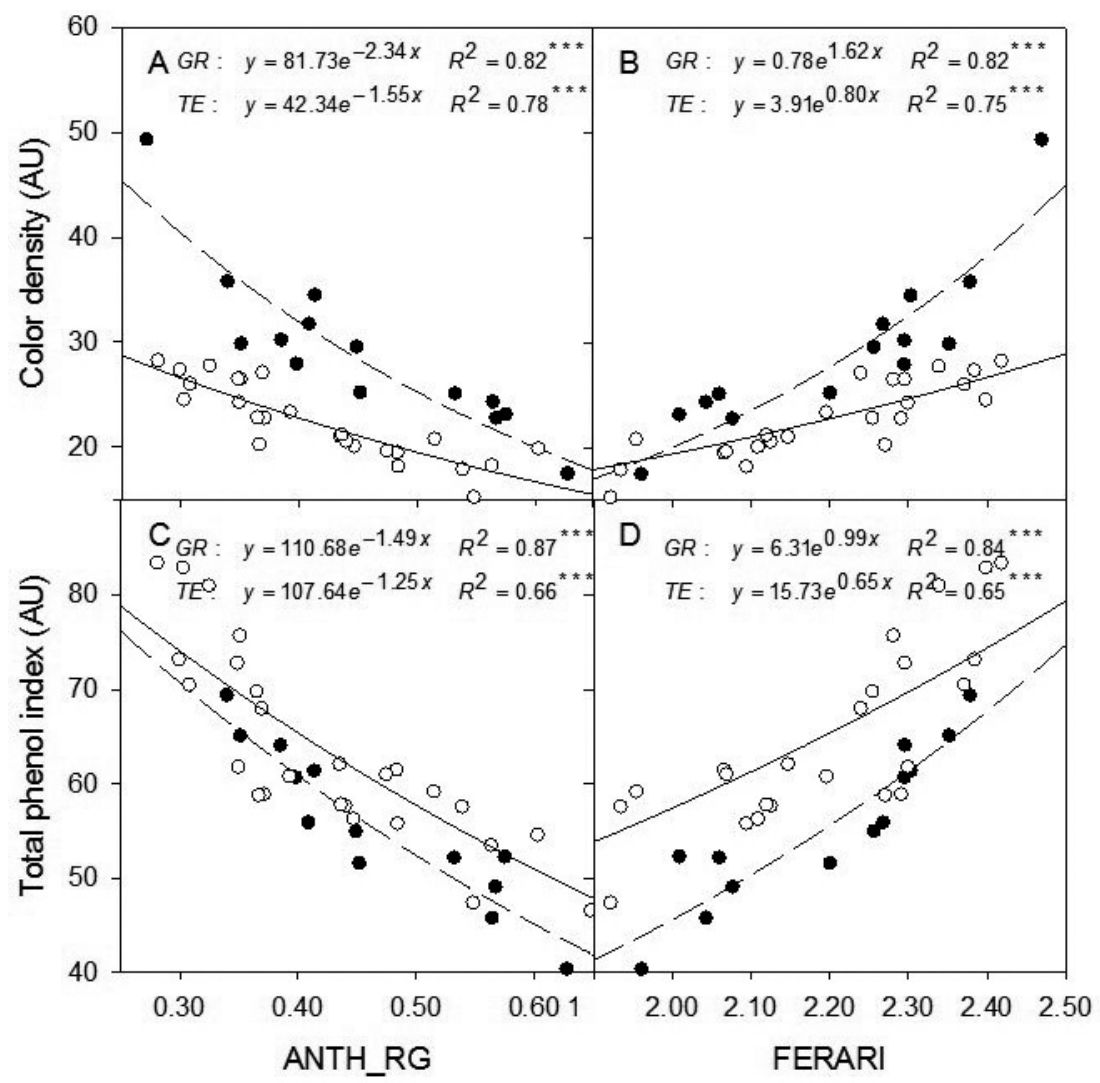

Figure 2 - The relationship between the wine color density (A, B) and total phenol index (C, D) and the fluorescence indices, ANTH_RG (A, C) and FERARI (B, D), determined at the winery on clusters from each fermentation lot, for Graciano (GR, black dots) and Tempranillo (TE, TM white dots) cultivars at site 1 (season 2009). ANTH_RG and FERARI values represent averages per fermentation lot (15 measurements). Lines represent the exponential regressions for Graciano (dashed line) and Tempranillo (continuous line). Coefficients of determination $\left(\mathbf{R}^{2}\right)$ and their statistical significance: *, **, *** indicate statistical significance at $P<0.05, P<0.01$, or $P<0.001$, respectively. $(n=25$ for Tempranillo and $n=14$ for Graciano).

estimations of the wines' color and phenolic features, and the $\mathrm{R}^{2}$ values were in the range of those reported in previous works, where wet chemistry procedures were used to determine the grape anthocyanin content (Iland, 1987; GonzálezNeves et al., 2004, 2010; Romero-Cascales et al., 2005; Jensen et al., 2008; Kontoudakis et al., 2010). From these works, significant linear correlations between grape anthocyanins and wine CD were reported, with $\mathrm{R}^{2}=0.82$ in Iland (1987) and $\mathrm{R}^{2}=0.92$ in Jensen et al. (2008), who studied eight different Vitis vinifera L. cultivars. Kontoudakis et al. (2010) compared four methods of extraction and analysis of grape anthocyanins for their predictive capabilities of wine CD and total phenols in several varieties. These authors reported $\mathrm{R}^{2}$ values for wine $\mathrm{CD}$ ranging from 0.39 (ITV method; Dupuch et al., 1993) to 0.95 (modified Cromoenos method; Gracia-Romeo, 2002) and for TPI ranging from 0.80 to 0.88 . Similarly,
González-Neves et al. (2010) also described R² values around 0.95 for the estimation of $C D$ and varying from 0.65 to 0.89 for TPI. On this matter, it is important to point out that all these wet chemistry procedures for the determination of grape anthocyanins require berry sampling, are very labor- and time-consuming, and should be carried out by well-trained technicians. These disadvantages may be mostly overcome by using the fluorescence sensor, whose measurements are non-invasive, fast and very easy (no manipulation of the sample is required).

Differences between the two cultivars, Graciano and Tempranillo, or even between seasons for a given cultivar, in the values of the $a$ and $b$ coefficients of the exponential functions $\left(y=a \cdot e^{b x}\right)$, could be reflecting differences in anthocyanin extraction during wine fermentation, which is greatly influenced by the grape maturity (Glories, 
1984), the skin-to-pulp ratio (Saint-Cricq de Gaulejac et al., 1998), and the level of skin cell degradation at the time of winemaking (RomeroCascales et al., 2005; Fulcrand et al., 2006).

When comparing Figures 1 and 2 it can be said that stronger correlations between the wine color and phenolic variables and the fluorescence indices were generally observed when ANTH_RG and FERARI were measured in the winery rather than in the vineyard, despite the fact that measurements were made on clusters in both conditions. In this way, the fruit measured in the winery represented $50 \%$ of the grapes of each fermentation lot, whereas in the vineyard, only three clusters per vine were determined, corresponding to $\sim 15 \%$ of the fruit of a fermentation lot. On this matter, increasing the number of fluorescence measurements in the vineyard by measuring a larger number of clusters per vine should improve the correlations. In this regard, the fluorescence sensor enables taking a quite large number of in-field measurements, necessary for a more robust sampling, given its fast and non-destructive operation mode.

The values of the slope, intercept and $\mathrm{R}^{2}$ of the relationships between the rectangular and cylindrical CIELAB coordinates for the Tempranillo wines obtained from site 2 and ANTH_RG and FERARI determined in the vineyard are presented in Table $2 . \mathrm{L}^{*}, \mathrm{~b}^{*}$ and $\mathrm{h}^{*}$ showed significant relationships with the two fluorescence indices, with $\mathrm{R}^{2}$ values in the range of 0.55 to 0.74 , although the sign of the correlations was opposite for ANTH_RG and FERARI. This inverse behavior of ANTH_RG to FERARI is to be expected, and is a proof that measurements were properly taken, since in the decreasing part of the response curve of ANTH_RG, this index decreased while FERARI increased, no matter the variable to which these fluorescence indices were compared (Cerovic, personal communication).

While the CIELAB color space is not very often used in day-to-day winemaking, their parameters offer a precise description of the wine color (Prodanov et al., 2005; Esparza et al., 2009). Intensely colored wines are generally made from grapes rich in anthocyanins (low ANTH_RG and high FERARI values) and described by low values of L* (Pérez-Magariño and González-San José, 2003; Esparza et al., 2009). On the other hand, $\mathrm{h}^{*}$ and coordinates $a^{*}$ and $b^{*}$ refer to the wine hue, which represents the contribution of the red, green, blue and yellow components. These components are affected by different factors, such as the anthocyanin profile or concentration of each individual anthocyanin (Han et al., 2008), the wine $\mathrm{pH}$ (Boulton, 2001), age and exposure to oxygen (Monagas et al., 2006), and the extent of anthocyanin copigmentation and polymerization with other polyphenols (Gil-Muñoz et al., 1997; Boulton, 2001; González-Manzano et al., 2008).

The negative values of the $b^{*}$ coordinate are reflecting the wines blue character, typical in very young wines, as those measured in this work (color determination was conducted several days after the wines were racked-off and no malolactic fermentation was allowed). Similarly, $b^{*}$ has been

Table 2 - Relationship between the wines rectangular and cylindrical CIELAB coordinates, lightness $\left(\mathrm{L}^{*}\right)$, green-red coordinate $\left(a^{*}\right)$, yellow-blue coordinate $\left(b^{*}\right)$, hue angle $\left(h^{*}\right)$ and chroma $\left(C^{*}\right)$, and the fluorescence indices,

ANTH_RG and FERARI, determined in the vineyard on three vines per experimental block (three clusters per vine) for Tempranillo at site 2 (season 2010). ANTH_RG and FERARI values represent averages per field experimental block ( 3 vines $x 3$ clusters per vine). Slope, intercept and coefficient of determination $\left(R^{2}\right)(n=13)$. Statistical significance is expressed as follows : $(*)$ for $P<0.05,(* *)$ for $P<0.01$ and $(* * *)$ for $P<0.001$. ns : non significant.

\begin{tabular}{|ccccccc|}
\hline CIELAB & \multicolumn{3}{c}{ ANTH_RG } & \multicolumn{3}{c|}{ FERARI } \\
\hline coordinate & slope & intercept & $\mathrm{R}^{2}$ & slope & intercept & $\mathrm{R}^{2}$ \\
\hline $\mathrm{L}^{*}$ & 62,14 & 27,12 & $0.73^{* * *}$ & $-16,83$ & 80,65 & $0.69^{* * *}$ \\
$\mathrm{a}^{*}$ & 12,97 & 48,6 & $0.07 \mathrm{~ns}$ & $-1,82$ & 56,48 & $0.02 \mathrm{~ns}$ \\
$\mathrm{~b}^{*}$ & $-44,03$ & 6,26 & $0.74^{* * *}$ & 10,64 & $-29,18$ & $0.55^{* *}$ \\
$\mathrm{C}^{*}$ & 20,2 & 46,88 & $0.16 \mathrm{~ns}$ & $-3,61$ & 60,66 & $0.06 \mathrm{~ns}$ \\
$\mathrm{~h}^{*}$ & $-0,77$ & 0,1 & $0.74^{* * *}$ & 0,19 & $-0,53$ & $0.58^{* *}$ \\
\hline
\end{tabular}


found to be negative or close to zero in the grape skins of several red Italian varieties (Rolle and Guidoni, 2007) as well as in very young wines (less than 20 days from the completion of alcoholic fermentation) of Monastrell (Almela et al., 1996) and one-month-old wines of Tempranillo, Graciano and Cabernet-Sauvignon (Monagas et al., 2006). From the $\mathrm{R}^{2}$ values shown in Table 2 , it seems that ANTH RG and FERARI also had a good prediction capability of coordinate $b^{*}$, which relates to the blue-to-yellow contribution. Other authors have also emphasized the importance of the $\mathrm{L}^{*}, \mathrm{~b}^{*}$ and $\mathrm{h}^{*}$ coordinates in the description of the colorimetric features of young red wines (GilMuñoz et al., 1997; Monagas et al., 2006). In this way, Gil-Muñoz et al. (1997) reported Pearson correlation coefficients of $-0.81,0.96$ and 0.94 between the wine $\mathrm{CD}$ and the coordinates $\mathrm{L}^{*}, \mathrm{~b}^{*}$ and $\mathrm{h}^{*}$, respectively, whereas the $\mathrm{r}$ value for $\mathrm{a}^{*}$ was 0.32 . On the other hand, better correspondence between grape anthocyanins and CIELAB coordinates were observed for $\mathrm{L}^{*}$ and $\mathrm{a}^{*}$ than for b* (González-Neves et al., 2010), although in this work the wines were analyzed two months after fermentation.

Neither $\mathrm{a}^{*}$ nor $\mathrm{C}^{*}$ coordinates could be estimated from the ANTH_RG and FERARI indices in the studied wines. The prevalence of the $b^{*}$ component in very young, purple wines might have interfered in the estimation of $a^{*}$ (red-green contribution) in the early stages of the wine life. Since the $C^{*}$ coordinate is the square root of $\left(a^{* 2}+b^{* 2}\right)$, and $a^{*}$ absolute value is much larger than $b^{*}$ in our wines, $\mathrm{C}^{*}$ is therefore meant to behave like $\mathrm{a}^{*}$. To better ascertain whether $a^{*}$ and $C^{*}$ could be better estimated from the fluorescence indices in later stages of the wine life, the time course of the CIELAB coordinates and their relationship at each time point with the ANTH_RG and FERARI values determined in the grapes should be further investigated in future works.

The vineyard and winery measurements of the fluorescence indices may be oriented to two different practical utilities for the wine industry. Field measurement of ANTH_RG and FERARI prior to harvest would help the grapegrower and winemaker in designing differentiated harvesting zones according to the anthocyanin and phenolic concentrations of the berries. On the other hand, winery measurements would simulate the scenario of the grape bins entering the winery that could be sorted into different fermentation tanks for different final wine color and phenolic features.

\section{CONCLUSIONS}

The results presented in this work show that a satisfactory estimation of the final wine color and phenolic characteristics can be obtained from fast, non-destructive fluorescence measurements of the fruit. The use of the fluorescence sensor in the vineyard, for precision viticulture, or at the winery crush pad could help the wine industry in optimizing harvesting and winemaking decisions, as well as in reducing time and labor costs.

Acknowledgments: The authors want to thank Force-A and its team for their help and financial support. Our gratitude also goes to Zoran Cerovic and Belén Ayestarán for their advices and Rodrigo Marin for collaborating with the fluorescence measurements.

\section{REFERENCES}

Agati G., Meyer S., Matteini P., Cerovic Z.G., 2007. Assessment of anthocyanins in grape (Vitis vinifera L.) berries using a non invasive chlorophyll fluorescence method. J. Agric. Food Chem., 55, 1053-1061.

Almela L., Javaloy S., Fernández-López J.A., LópezRoca J.M., 1996. Varietal classification of young red wines in terms of chemical and colour parameters. J. Sci. Food Agric., 70, 173-180.

Baluja J., Diago M.P., Goovaerts P., Tardaguila J., 2012. Assessment of the spatial variability of anthocyanins in grapes using a fluorescence sensor: relationships with vine vigour and yield. Precis. Agric., 13, 457-472; doi: 10.1007/s 11119-0129261-x.

Ben Ghozlen N., Cerovic Z.G., Germain C., Toutain S., Latouche G., 2010a. Non-destructive optical monitoring of grape maturation by proximal sensing. Sensors, 10, 10040-10068.

Ben Ghozlen, N., Moise, N., Latouche, G., Martinon, V., Mercier, L., Besancon, E., Cerovic, Z.G. $2010 \mathrm{~b}$. Assessment of grapevine maturity using a new portable sensor: Non-destructive quantification of anthocyanins. J. Int. Sci. Vigne Vin, 44, 1-8.

Boulton R. 2001. Copigmentation of anthocyanins and its role in the color of red wine: A critical review. Am. J. Enol. Vitic., 52, 67-87.

Bramley, R.G.V., Le Moigne M., Evain S., Ouzman J., Florin L., Fadaili E.M., Hinze C.J., Cerovic Z.G., 2011. On-the go sensing of grape berry anthocyanins during commercial harvest: development and prospects. Aust. J. Grape Wine Res., 17, 316-326.

Campo E., Ballester J., Langlois J., Dacremont C., Valentin D., 2010. Comparison of conventional descriptive analysis and a citation frequency-based 
descriptive method for odor profiling: an application to Burgundy Pinot noir wines. Food Qual. Prefer., 21, 44-55.

Carreño, J., Martinez, A., Almela, L., Fernandez-Lopez, J.A. 1995. Proposal of an index for the objective evaluation of the colour of red table grapes. Food Res. Int., 28, 373-377.

Cerovic Z.G., Moise N., Agati G., Latouche G., Ben Ghozlen N., Meyer S., 2008. New portable optical sensors for the assessment of winegrape phenolic maturity based on berry fluorescence. J. Food Comp. Anal., 21, 650-654.

CIE Colorimetry, Second Edition. 1986. Publication C.I.E. no. 15.2

Cozzolino D., Dambergs R.G., Janik L., Cynkar W.U., Gishen M., 2006. Analysis of grapes and wine by near infrared spectroscopy. J. Near Infrared Spectrosc., 14, 279-289.

Dupuch V. 1993. Appréciation de la matière phénolique des vins rouges : application à la détermination de la date de récolte. In: Proceedings of the Symposium "Journée technique du CIVB", January 21, 1993, Bordeaux (France), pp. 62-69.

Esparza I., Santamaria C., Calvo I., Fernandez J.M., 2009. Significance of CIELAB parameters in the routine analysis of red wines. CyTA - J. Food, 7, 189-199.

Fernandes A.M., Oliveira P., Moura J.P., Oliveira A.A., Falco V., Correia M.J., Melo-Pinto P., 2011. Determination of anthocyanin concentration in whole grape skins using hyperspectral imaging and adaptive boosting neural networks. J. Food Eng., 105, 216-226.

Ferrer-Gallego R., Hernandez-Hierro J.M., RivasGonzalo J.C., Escribano-Bailon M.T., 2011. Determination of phenolic compounds of grape skins during ripening by NIR spectroscopy. $L W T$ Food Sci. Technol., 44, 847-853.

Fulcrand H., Dueñas M., Salas E., Cheynier V., 2006. Phenolic reactions during winemaking and aging. Am. J. Enol. Vitic., 57, 289-297.

Garcia-Marino M., Escudero-Gilete M.L., EscribanoBailon M.T., González-Miret M.L., RivasGonzalo J.C., Heredia F.J., 2012. Colorimetric characteristics of the phenolic fractions obtained from Tempranillo and Graciano wines through the use of different instrumental techniques. Anal. Chim. Acta, 732, 153-161.

Gil-Muñoz R., Gómez-Plaza E., Martínez A., LópezRoca J.M., 1997. Evolution of the CIELAB and other spectrophotometric parameters during wine fermentation. Influence of some pre and postfermentative factors. Food Res. Int., 30, 699705.
Glories Y., 1984. La couleur des vins rouges. 2. Mesure, origine et interprétation. Conn. Vigne Vin, 18, 253271.

González-Caballero V., Sánchez M.T., López M.I., Pérez-Marín D., 2010. First steps towards the development of a non-destructive technique for the quality control of wine grapes during on-vine ripening and on arrival at the winery. J. Food Eng., 101, 158-165.

González-Manzano, S., Santos-Buelga, C., Dueñas, M., Rivas-Gonzalo, J.C., Escribano-Bailón, T. 2008. Colour implications of self-association processes of wine anthocyanins. Eur. Food Res. Technol., 226, 483-490.

González-Neves G., Charamelo D., Balado J., Barreiro L., Bochicchio R., Gatto G., Gil G., Tessore A., Carbonneau A., Moutounet M., 2004. Phenolic potential of Tannat, Cabernet-Sauvignon and Merlot grapes and their correspondence with wine composition. Anal. Chim. Acta, 513, 191-196.

González-Neves G., Gil G., Ferrer M., Charamelo D., Balado J., Bochicchio R., Gatto G., Tessore A. 2010. Prediction of the colour and polyphenolic composition of the young red wines from the phenolic potential of the grapes. Int. J. Food Sci. Technol., 45, 1843-1851.

Gracia-Romeo J.P., November 2002. Colorimetric method for determining the color of wine from the grape. European patent. EP 1324016, US Patent $7,301,635$.

Han F.L., Zhang W.N., Pan Q.H., Zheng C.R., Chen H.Y., Duan C.Q., 2008. Principal component regression analysis of the relation between CIELAB color and monomeric anthocyanins in young Cabernet Sauvignon wines. Molecules, 13, 2859-2870.

Iland P.G., 1987. Predicting red wine colour from grape analysis. Aust. Grapegrow. Winemak., 285, 29.

Iland P., Bruer N., Edwards G., Weeks S., Wilkes E., 2004. Chemical analysis of grapes and wine: techniques and concepts. Patrick Il and Wine Promotions, Campbelltown, Australia.

Jensen J.S., Demiray S., Egebo M., Meyer A.S., 2008. Prediction of wine color attributes from the phenolic profiles of red grapes (Vitis vinifera). $J$. Agric. Food Chem., 56, 1105-1115.

Kennedy J.A. 2010. Wine colour. In: Managing wine quality, Vol. 1. A.G. Reynolds (Ed.), Cambridge: Woodhead Publishing, pp. 73-104.

Kontoudakis N., Esteruelas M., Fort F., Canals J.M., Zamora F., 2010. Comparison of methods for estimating phenolic maturity in grapes: Correlation between predicted and obtained parameters. Anal. Chim. Acta, 660, 127-133.

Liang Z., Sang M., Fan P., Wu B., Wang L., Yang S., Li S., 2011. CIELAB coordinates in response to berry 
skin anthocyanins and their composition in Vitis. $J$. Food Sci., 76, 490-497.

Monagas M., Martín-Álvarez P.J., Gómez-Cordovés C., Bartolomé B., 2006. Time course of the colour of young red wines from Vitis vinifera L. during ageing in bottle. Int. J. Food Sci. Technol., 41, 892899.

Negueruela A.I., Echavarri J.F., Ayala F., 2001. Caractéristiques chromatiques. OIV Feuille Verte, no. 1102 .

OIV, 2009. Compendium of international methods of analysis of wines and musts. Organisation International de la Vigne et du Vin, Paris.

Pérez-Caballero V., Ayala F., Echávarri J.F., Negueruela A.I., 2003. Proposal for a new standard OIV method for determination of chromatic characteristics of wine. Am. J. Enol. Vitic., 54, 5962.

Pérez-Magariño S., Gonzalez-San Jose M.L., 2003. Application of absorbance values used in wineries for estimating CIELAB parameters in red wine. Food Chem., 81, 301-306.

Prodanov M.P., Dominguez J.A., Blazquez I., Salinas M.R., Alonso G.L. 2005. Some aspects of the quantitative/qualitative assessment of commercial anthocyanin-rich extracts. Food Chem., 90, $585-$ 596.

Rolle L., Guidoni S. 2007. Color and anthocyanin evaluation of red winegrapes by CIE L*, a*, b* parameters. J. Int. Sci. Vigne Vin, 41, 193-201.

Romero-Cascales I., Ortega-Regules A., López-Roca J.M., Fernández-Fernández J.I., Gómez-Plaza E. 2005. Differences in anthocyanin extractability from grapes to wines according to variety. Am. J. Enol. Vitic., 56, 212-219.

Saint-Cricq de Gaulejac N., Vivas N., Glories Y., 1998. Maturité phénolique : définition et contrôle. Rev. Franc. Oenol., 173, 22-25.

Sampaio T.L., Kennedy J.A., Vasconcelos M.C., 2007. Use of microscale fermentations in grape and wine research. Am. J. Enol. Vitic., 58, 534-539.

Somers T.C., Evans M.E., 1974. Wine quality: Correlations with colour density and anthocyanin equilibria in a group of young red wines. J. Sci. Food Agric., 25, 1369-1379.

Tuccio L., Remorini D., Pinelli P., Fierini E., Tonutti P., Scalabrelli G., Agati G., 2011. Rapid and nondestructive method to assess in the vineyard grape berry anthocyanins under different seasonal and water conditions. Aust. J. Grape Wine Res., 17, 181-189. 